\title{
Questions and Comments
}

about the Methodology and Conclusions

in 'Comparative Room Burn Study

of Furnished Rooms from the United

Kingdom, France and the United States',

by Blais et al. 2019

Vytenis Babrauskas*, Fire Science and Technology Inc, 160 Cabrini Blvd, New York, NY 10033, USA

Kathryn M. Rodgers, Silent Spring Institute, 320 Nevada Street, Suite 302,

Newton, MA 02460, USA

Donald Lucas, Green Science Policy Institute, P.O. Box 5455, Berkeley,

CA 94705, USA and Lawrence Berkeley National Laboratory (Retired),

1 Cyclotron Road, Berkeley, CA 94720, USA

Rebecca Fuoco, Green Science Policy Institute, P.O. Box 5455, Berkeley,

CA 94705, USA

Dear editor,

We have concerns about the Blais et al. paper "Comparative Room Burn Study of Furnished Rooms from the United Kingdom, France and the United States" in the March 2020 issue of Fire Technology [1]. The study compared fire growth and smoke toxicity in mock burn rooms each containing a couch and chair purchased from either the United Kingdom, France, or the United States. The authors use the results to draw conclusions about the efficacy of the countries' furniture flammability standards. Unfortunately, the paper was plagued by a number of design flaws, omissions, and conflicts of interest. Our main concerns are summarized briefly here and described in detail below.

1. The study introduced potential confounding variables into the burn rooms, including a flat screen television.

2. The authors fail to identify the chemicals used as flame retardants in the individual items in each room.

3. The toxicity analysis that was done does not serve to quantify the problem.

4. The authors do not appropriately review the scientific literature on the efficacy of code provisions of home furnishings and electronics.

\footnotetext{
*Correspondence should be addressed to: Vytenis Babrauskas, E-mail: vytob@doctorfire.com
} 
5. The burn rooms do not accurately reflect real fire environments.

6. This study was funded by the North American Fire-Retardant Association and the American Chemistry Council, which should be noted as conflict of interest, not merely an acknowledgement.

\section{Confounding Variables were Introduced into the Burn Rooms}

Blais et al. attempted to compare the fire safety of furniture from countries with a smolder-only flammability standard (France and the United States) against furniture from a country with a combination open-flame and smolder standard (the United Kingdom). However, the comparison was blurred by, among other problems, confounding variables in the experimental burn rooms.

For example, each burn room had a flat panel television purchased in the same country as the room's couch and chair. Although the authors say the televisions "appeared to be identical," the chemical analysis of the television casings showed different levels of bromine, phosphorus, and antimony among the televisions. This suggests that the televisions did not have identical compositions of flame retardant chemicals. Further, the weight of the televisions purchased in France was significantly less than that of the televisions purchased in the United Kingdom and the United States.

Further, the results would most likely change if there were different conditions used, such as: different placement of objects, room size, ventilation, window placement and type, ceiling height, different ignition sources, and especially different placement of ignition sources. In the heat release rate experiments, the order of crib 5 and crib 6 ignition reversed. The authors suggest this could be due to the different geometries of the two cribs (one being narrower), illustrating that the size of the ignition source produces different results. This shows how subtle differences in ignition configuration affects the non-linear combustion processes.

\section{The Authors Failed to Identify the Flame Retardant Chemicals used in the Burned Items}

While the study determined elemental compositions of the televisions and couch cushion filling and foam (specifically concentrations of bromine, chlorine, phosphorus, and antimony), the exact chemicals used as flame retardants and their loadings were not identified. The experimental design only compares one manufacturer's choice of flame retardant(s) for one product line in the three markets. Those choices may not be representative of how the industry at large complies with those markets' flammability standards, or even of the manufacturer's other product lines. Even without confounders the results only speak to the performance of the specific flame retardants at specific loadings in this product lineand those flame retardants are not even identified. Such omission makes the study 
irreproducible, since no other researchers would be able to investigate whether or not the authors' findings can be reproduced.

Further, Blais et al.'s conclusions are contradicted by stronger studies. For example, McKenna et al. compared the fire growth and smoke toxicity of three different sofa-beds that met the United Kingdom's standard three different ways [2]. Due to significantly higher smoke toxicity, the authors concluded that the sofa-beds that used chemical flame retardants to the meet the standard presented a greater fire danger than the sofa-bed that used natural materials and a technical weave.

The identity of the flame retardants used is also necessary for a proper riskbenefit analysis. The health and safety concerns of organohalogen flame retardants are well documented [3]. Extensive risk-benefit analyses have concluded that their health harm greatly outweighs any potential fire safety benefit, and that there often is no measurable fire safety benefit at all [3, 4]. The organophosphate flame retardants that are increasingly used as replacements appear to show toxicity concerns similar to prior-used organohalogen chemicals [5]. It should be noted that many flame retardant chemicals, such as PBDEs, have been banned or withdrawn from the market, in spite of assurances that they were safe to use when they were manufactured. Unfortunately, the health effects research requires many years of study, so some health effects do not become obvious for decades.

\section{The Toxicity Analysis that was Done Does Not Serve to Quantify the Problem}

Longer-term toxicity associated with smoke is difficult to determine. In the paper's discussion of dioxins and furans, the authors state that "concentration data by themselves, however, do not enable prediction of toxicity to humans. Synergistic, additive, and/or antagonistic effects make prediction of toxicity highly uncertain without actual toxicity testing." Indeed, actual toxicity testing is difficult due to different exposure pathways. While acutely toxic chemicals such as hydrogen cyanide (HCN) should be measured on as short of a time scale as possible, for chemicals with longer-term toxicity, the time release measurements are not as important. Knowing the flame retardant composition of the items in each room would allow for a better estimate of potential exposures and associated health effects.

Toxic gases can exceed dangerous levels for acute exposures, but their concentration is dependent on the sampling location, making it difficult to determine what the actual levels are. Toxic gases such as HCN can be an important factor in fire deaths, since the immediately dangerous to life and health (IDLH) value is $50 \mathrm{ppm}$. HCN was seen in all room burns, with peak values exceeding $1000 \mathrm{ppm}$. The important measure here should be when the IDLH value is exceeded, not when the peak concentration is reached. The gas was detected at the door but not in the center of the room, showing how the sampling location can be important. The room center was measured at $0.457 \mathrm{~m}$ from the floor, which is well below the breathing height level even for a seated person. The point is that stratification of gases or measurement techniques can produce widely different results, as the 
authors demonstrated. But neither location is at all indicative of hazard to actual occupants, who will tend to crouch underneath the smoke layer, if possible, and drop to all fours when this becomes impossible.

\section{Controversy Surrounding Efficacy of Code Provisions for Home Furnishings and Electronics is Not Sufficiently Acknowledged}

The authors acknowledge the "controversy surrounds fire codes associated with home furnishings and electronics," but do not adequately cite or describe the large body of science behind it [6].

There is strong evidence that open flame standards necessitating the use of flame retardants in furniture foam are ineffective. For example, Babrauskas studied furniture where the peak HRR of identically-constructed furniture passing California's previous open flame standard (TB117) was compared to furniture made with non-flame-retardant (non-FR) foam [7]. The differences observed between the furniture with non-FR foam and furniture made with foam complying with TB117 were within the normal data scatter from this type of test. In addition, visually the fire development over the furniture was identical. The Consumer Product Safety Commission conducted similar tests and reached the same conclusions [8].

The authors claim that "[s]ignificant fire risk is associated with large flat panel televisions," but this is not supported by data. Flame retardants were first added to television enclosures in the mid-1970s to meet UL 1410, which protected against internally-initiated fires [9]. The likelihood of such fires was far greater at that time with the very high voltages required by early cathode ray tube technology. Today's televisions are flat panel displays with either liquid crystal or plasma display panel technologies. This change in technology has effectively eliminated the high-voltage/high-temperature hazard.

We further note that the authors' description of the underlying regulatory requirements as being "fire code" provisions is incorrect. Fire codes (e.g., NFPA 1 or the International Fire Code) regulate primarily how buildings should be safely operated and maintained. They are not the mechanism by which combustion behavior of occupant goods is normally regulated. In the U.S., combustion behavior of occupant goods is primarily regulated by Underwriters Laboratories (UL) standards, while furniture and bed products are primarily governed by the Consumer Product Safety Commission (CPSC) and State of California regulations (e.g., TB 117-2013). In the UK, regulation of furniture combustion behavior has been through Statutory Instruments which, again, are not a fire code.

Furthermore, the authors acknowledge that their results "directly contradict results published by [2]". There is no explanation as to why the results are so diametrically different. Stark differences such as these need to be discussed in much more detail. One must consider the possibility that the differences arise due to the authors' affiliation. 


\section{The Experimental Design is Not Able to Reflect Differences in Real-World Fires}

In order to interpret the study's implications for fire safety, it is important to ask if the fire conditions in this study are representative of fires in the US and EU. Both the EU and US statistics show that small open flames are the ignition source in a small fraction of room fires (roughly $7 \%$ for candles + open flames in the EU [10], 3\% from candles in the US [11]). Note that NFPA does not list other open flame ignition sources in their publications on this subject. There is substantial evidence from both the EU [12] and the US that most fire deaths from room fires are a result of cigarettes and smoking materials. This remains true, despite use of reduced ignition propensity (RIP) or FSC cigarettes, which ostensibly minimize ignitions. We could not find the statement "fires where the furnishings in living rooms are the first item ignited are a leading cause of fire deaths" in the 2018 NFPA report cited [13]. The NFPA has a newer report for fire deaths during 2019 that was published in the fall of 2020 [14]. Yet, the more recent report also does not make this statement.

Ignition does not always occur between the seat cushion and backing, as in the study's experiments. Ignition at the arm of a sofa, in the center of the cushion, or underneath the furniture can significantly change fire behavior. Real fires are complex events, and even small changes can seriously affect the results [15].

Also, the authors assumed traditional type of housing, with individual rooms for each function. Newer building in the US often use "open floor" concepts, where family rooms, living rooms, kitchens, and dining rooms constitute one unpartitioned volume. This shows the difficulty of performing tests covering the wide range of real-life conditions.

It is of serious concern that the British sofa showed failure in the British standard BS 5852. Since the sofa was manufactured by a very large international company, it is hard to understand if the product was not tested properly, or that the authors' test procedures did not duplicate exactly the BS 5852 standard. These are remarkably disturbing results, and the authors did nothing to explain this anomaly.

\section{The Study's Funding Sources are Not Disclosed as Conflicts of Interest}

We believe a Conflict of Interest disclosure should accompany this article, as is common for Springer journals. The funding of this study by the North American Fire Retardant Association and the American Chemistry Council represents "a real or apparent conflict of interest," as both organizations have a financial interest in promoting the use of chemical flame retardants.

\section{Compliance with Ethical Standards}

Conflicts of interest All authors declare no competing financial interests. 


\section{References}

1. Blais MS, Carpenter K, Fernandez K (2020) Comparative room burn study of furnished rooms from the United Kingdom, France and the United States. Fire Technol 56:489-514. https://doi.org/10.1007/s10694-019-00888-8

2. McKenna S, Birtles R, Dickens K, Walker R, Spearpoint M, Stec A (2018) Flame retardants in UK furniture increase smoke toxicity more then they reduce fire growth rate. Chemosphere 2018(196):429-439. https://doi.org/10.1016/j.chemosphere.2017. 12.017

3. Shaw SD, Blum A, Weber R, Kanna K, Rich D, Lucas D, Koshland CP, Dobraca D, Hanson S, Birnbaum LS (2010) Halogenated flame retardants: do the fire safety benefits justify the risks?. Rev Environ Health 25:261-305. https://doi.org/10.1515/ reveh.2010.25.4.261

4. Babrauskas V, Blum A, Daley R, Birnbaum L (2011) Flame retardants in furniture foam: benefits and risks. In: Fire Safety Science-Proceedings of the 10th international symposium, international association for fire safety science, pp 265-278, London (2011). DOI: https://doi.org/10.3801/IAFSS.FSS.10-265

5. Blum A et al (2019) Organophosphate ester flame retardants: are they a regrettable substitution for polybrominated diphenyl ethers?. Environ Sci Technol Lett 6(11):638-649. https://doi.org/10.1021/acs.estlett.9b00582

6. Charbonnet JA, Weber R, Blum A (2020) Flammability standards for furniture, building insulation and electronics: benefits and risks. Emerg Contam. https://doi.org/ 10.1016/j.emcon.2020.05.002

7. Babrauskas V (1983) Upholstered furniture heat release rates: measurements and estimation. J Fire Sci 1:9-32. https://doi.org/10.1177/073490418300100103

8. Upholstered Furniture Full Scale Chair Tests-Open Flame Ignition Results and Analysis, CPSC (2012). https://www.cpsc.gov/s3fs-public/ufmemos.pdf

9. Babrauskas V (2003) Ignition handbook. Fire Science Publishers/Society of Fire Protection Engineers, Issaquah WA

10. Hagen R (2019) Presentation at the furniture fire safety symposium in Brussels, Belgium. https://www.modernbuildingalliance.eu/european-fire-safety-week-2019-agenda-an d-registration-for-the-building-day/

11. Ahrens M (2011) Home Structure Fires that Began with Upholstered Furniture, National Fire Protection Association, NFPA. https://nfpa.org/-/media/Files/Codes-andstandards/standards-council/March-2014/SC_SupAgenda_Part2_03_14.ashx

12. Särqvist S (2020) Private communication

13. Evarts B (2018) Fire loss in the united states during 2017, national fire protection association. https://www.nfpa.org/-/media/Files/News-and-Research/Fire-statistics-and-repor ts/US-Fire-Problem/Old-FL-LL-and-Cat/FireLoss2018.ashx

14. Ahrens M, Evarts B (2020) Fire Loss in the United States during 2019, National Fire Protection Association. https://www.nfpa.org/ /media/FD0144A044C84FC5 BAF90C05C04890B7.ashx

15. Mitler HE, Tu K-M (1994) Effect of ignition location on heat release rate of burning upholstered furniture. In: Proceedings of the annual conference on fire research, pp 121-122. NIST, Gaithersburg, MD. https://nvlpubs.nist.gov/nistpubs/Legacy/IR/nis tir5499.pdf

Publisher's Note Springer Nature remains neutral with regard to jurisdictional claims in published maps and institutional affiliations. 